\title{
Perbaikan Lambung Kapal KM. Harima PT. CSFI-Cilacap
}

\author{
Aris Sasongko Dwiono ${ }^{a}$, Andi Hendrawan ${ }^{b^{*}}$, Sri Pramono \\ a,b,Akademi Marititm Nusantara \\ 'Universitas Ivet \\ aEmail: aris_sasaongko@amn.ac.id \\ b*Email: andi_hendrawan@amn.ac.id \\ 'Email: sripramono@amn.ac.id
}

\begin{abstract}
ABSTRAK
Tujuan pengoperasian sebuah kapal adalah untuk transportasi atau pemindahan barang, namun hal yang tidak kalah pentingnya adalah keselamatan. Karenanya pengecekan setiap bagian kapal menjadi sangat penting. Perbaikan lambung kapal suaru keharusan karena kerusakan pada lambung kapal dapat mengakibatkan ketidakseimbangan operasi kapal bahkan kecelakaan kapal. Penelitian ini bertujuan untuk mendiskripsikan perbaikan lambung kapal pada Kapal KM. Harima PT. CSFI Cilacap. Penelitian menggunakan metode survei dengan melihat dan terlibat langsung dalam proses perbaikan kapal. Perbaikan yang dimaksud sesuai tujuan penelitian adalah perbaikan lambung kapal KM Harima. Hasil menunjukkan bahwa perbaikan lambung kapal dilakukan melalui tahap pengecekan, pengelasan, sandblasting atau pembersihan dan pengecatan.
\end{abstract}

Kata Kunci: perbaikan, kapal, lambung

\section{ABSTRACT}

The purpose of a ship is for the transportation or transfer of goods, but what is no less important is safety. Therefore checking every part is very important. Repair of the hull is mandatory because damage to the hull can result in imbalance in ship operations and even ship accidents. This study aims to describe the repair of the ship's hull on the KM. Harima PT. CSFI Cilacap. The study used a survey method by observing and being directly involved in the ship repair process. Improvements that are in accordance with the research objectives are repairing the ship's hull KM Harima. The results show that ship repair is carried out through checking, welding, welding, or painting.

Keywords: repairs, ship, ship hull

\section{PENDAHULUAN}

Perkembangan perkapalan dalam dunia kemaritiman harus diikuti dengan peningkatan mutu alat transportasi. Kapal merupakan alat transportasi yang dipergunakan dalam menghubungkan daratan. Perawatan dan pemeliharaan kapal merupakan hal yang sangat penting. Karena dalam pengoperasian kapal memerlukan kondisi yang benarbenar baik dan layak untuk berlayar (Ariany, 2014). Kerusakan yang terjadi pada kapal, utamanya pada lambung kapal bisa memengaruhi kinerja kapal yang akan mengakibatkan kebocoran. Apabila lambung kapal mengalami keretakan dan kebocoran sehingga laju kapal akan terhambat dikarenakan ada kerak dan kebocoran. Kerusakan dialami oleh kapal bisa dikarenakan tubrukan (collision) atau kandas (grounding), yang pada akhirnya menimbulkan gangguan keselamatan kapal dan lingkungan di sekitar. 
Lambung kapal adalah bagian kapal yang memengaruhi daya apung kapal. Daya apung tersebut mempunyai fungsi sebagai kekuatan yang akan menopang beban yang berasal dari penumpang serta isi muatan kapal. Nilai besaran daya apung akan menentukan berat muatan yang akan ditanggung oleh kapal tersebut (Satoto et al., 2013).

Peningkatan keselamatan struktur kapal dan upaya meminimalisasi resiko, maka International Maritime Organization (IMO) memberikan persyaratan dalam Non Convention Vassel Standart (NCVS). Merupakan tugas distrik navigasi untuk menganalisa kekuatan sisa pasca kerusakan lambung kapal. Lambung yang normal memiliki netralisasi yang bergerak searah sumbu vertikal dan horizontal pada saat progressive collapse yang dibebani momen lentur vertikal dan penampang yang simetris.

Jika penampang lambung kapal mengalami kerusakan yang disebabkan karena tubrukan, dan mengakibatkan sumbu netral berputar terhadap sumbu horizontal kapal. Kondisi ini akan memengaruhi nilai tegangan dan regangan pada sisi yang mengalami kerusakan. Penampang lambung yang rusak dibanding bagian sisi yang masih utuh sehingga bisa dianalisa seberapa besar kerusakannya. Penelitian ini bertujuan untuk menjelaskan bagaimana perbaikan lambung kapal KM. Harima di PT. CSFI Cilacap.

$$
\text { Perbaikan lambung kapal }
$$
merupakan pekerjaan dengan maksud memperbaiki lambung kapal yang rusak karena berbagai hal. Perbaikan yang dilakukan pada lambung kapal disebut replating. Replating adalah proses pergantian plat atau mengganti plat. Proses ini dilakukan dengan cara mengganti plat yang rusak dengan yang baru. Namun lambung kapal praktiknya tidak hanya pergantian plat saja, yang dilakukan adalah pergantian konstruksi diantaranya besi siku, pillar, dan lainnya.
Reparasi (repair) dapat dilakukan di dock atau galangan kapal. Reparasi juga bisa dilakukan di perairan atau terapung di atas air (floating). Perbaikan lambung kapal yang dilakukan di galangan kapal dapat melakukan perbaikan seluruh bagian lambung kapal dan bagian pendukungnya. Namun perbaikan atau reparasi yang dilakukan di atas air (floating) hanya sebatas pada bagian-bagian yang tidak terendam air.

Penyebab rusaknya lambung kapal dapat dijelaskan sebagai berikut:

1. Gesekan dan benturan dengan benda lain.

Pada peristiwa gesekan akan terjadi saat kapal bergerak pada laut yang dangkal. Bisa juga jika kapal lewat sungai pada saat air surut. Hal yang sering terjadi adalah gesekan dengan dasar perairan seperti: terumbu karang, batu, pasir, lumpur, tanah, dan gesekan dengan kapal yang karam. Deformasi akan terbentu sebagai akibat gesekan lambung kapal dengan plat bottom. Kapal bergerak terus dalam keadaan bergesekan akan menimbulkan robeknya lambung kapal. Pada akhirnya gesekan di bawah perairan akan fatal akibatnya dan akibatnya kapal akan berhenti atau kandas. Pada kondisi ini maka bisa dipastikan lambung kapal pada kondisi rusak parah.

Pada peristiwa benturan lambung kapal dapat berupa benturan antara kapal yang satu dengan lainnya atau benturan kapal dengan material yang ada di sekelilingnya; rambu, kayu, bongkahan es, batu karang, buoy atau gunung es. Kadang rusaknya lambung kapal juga karena benturan benda di tepi daratan seperti: pemecah ombak, dermaga, jety. Kerusakan bangunan kapal atau bulwark dan railling secara umum disebabkan oleh benturan antara kapal dengan muatan lainnya dan benturan hook dari crane pada saat proses bongkar muat.

2. Faktor alam

Faktor alam yang menjadi penyebab kerusakan lambung kapal 
antara lain; secara terus menerus lambung kapal dihantam gelombang laut. Hal ini terlihat plat nampak bergelombang berkarat bahkan frame terdesak ke arah dalam (cekung). Gelombang yang kuat bahkan akan menimbulkan lambung kapal patah. Selain gelombang kondisi air pasang (high tide) dan air surut (low tide) laut akan merusak bangunan kapal dan menimbulkan kerusakan meskipun kapal dalam kondisi tidak bergerak atau diam.

Beda potensial listrik pada bagian luar plat lambung kapal juga dapat menimbulkan kerusakan lambung kapal, Kerusakan yang bisa terjadi namlak plat akan nampak lubang-lubang kecil dan dangkal (pitted) yang jumlahnya tidak sedikit, bahan plat sangat berpengaruh terhadap pola kerusakan, semakin baik bahannya maka tingkat kerusakan juga makin kecil. Kerusakan bisa terjadi karena pengaruh biota laut dan rendaman yang terlalu lama karan kapal dalam kondisi off juga akan menimbulkan karat yang lebih cepat. .

3. Getaran yang berlebihan.

Getaran berlebih merupakan mekanisme kerusakan yang terjadi karena rambatan getaran terhadap badan kapal. Sumber adalah getaran mesin penggerak utama kapal dan mesin bantu lannnya. Getaran juga terjadi dikarenakan gelombang laut sebagai akibat benturan dengan baling baling.

Diperlukan desain yang maju agar getaran dapat diredam sehingga tidak mengakibatkan keretakan pada lambung kapal. Contoh keretakan dapat terjadinya karena lendutan pada poros propeller rusaknya daun baling baling (A. Hendrawan, 2019b), tata letak mesin pada kapal yang salah (proses alignment) saat posisi mesin tidak horizontal dengan poros baling baling.

4. Kesalahan manusia/Human error

Pengaruh dari kesalahan manusia cukup signifikan. Kesalahan dan kecerobohan manusia dapal pengerjaan di doks, contoh kesalahan dan pengelasan, sandblasting dan pengecetan. Ketelitian diperlukan agar hasil menjadi maksimal.

Beberapa kesalahan yang terjadi pada saat pengerjaan konstruksi kapal karena: proses air pressure test yang salah sehingga tekanan melampaui batas yang ditentukan, kerusakan yang terjadi; retak pada lambung, robek, dan pengelasan yang lepas dari bagian konstruksi.

a. Karat pada plat lambung kapal dengan lubang kecil. Plat lubang diuji, jika ternyata masih tebal, pergantian plat hanya sebagian kecil saja dengan mengganti plat yang berlubang. Caranya croping. ukuran plat minimum 300 x 300 $\mathrm{mm}$. Jika hasil pengujian diperoleh ketebalan plat di sekitar lubang telah tipis, diperlukan pergantian plat yang diperluas sampai batas ketebalan plat yang diinginkan dan aman.

b. Pada plat lambung kapal yang lubangnya mempunyai lubang yang luas maka pergantian plat dilaksanakan sesuai area kerusakan atau jika kerusakan hampir mencapai $3 / 4$ pada plat dari 1 lembar maka plat yang berlubang atau rusak diganti seluruhnya sampai batas sambungan antara plat atau seam welds.

c. Pengujian ultrasonic test diperlukan untuk mengetahui ketebalan plat. Jika hasil test memperlihatkan ketebalan plat kurang dari $20 \%$ maka plat harus diganti baru.

d. Pada plat deformasi dan terdesak kedalam. Bagian deformasi atau cekungan yang terdalam diukur, bila deformasi terjadi dengan kedalaman 2,5 x tebal plat $(\mathrm{mm})$ atau lebih diperlukan plat baru. Jika kerusakan deformasi belum mencapai 2,5 x tebal plat ( $\mathrm{mm}$ ) dan 
tidak curam atau landai maka plat tidak perlu diganti baru.

e. Pada plat lambung kapal jika terjadi deformasi atau terdesak kedalam dalam bentuk yang curam dengan kedalaman $20 \mathrm{~mm}$ maka plat diganti. Jika plat terjadi deformasi berada di belakang frame atau sekat, maka pengamatan selanjut diperlukan apakah telah mencapai deformasi $20 \%$ apa belum, jika mengalami hal tersebut maka plat harus diganti baru untuk menjamin keamanan.

f. Pada keadaan plat kulit terlipat atau berbentuk gelombang yang bersusun tapi tidak mengalami kebocoran perlu penggantian plat. Penentuan pergantian plat berdasarkan pengamatan dan rasionalisasi berdasarkan hasil diskusi apakah deformasi sudah sedemikian parah sebagai akibat gesekan dan benturan. Jika hasil observasi dan diskusi harus diganti plat maka keputusan terbaik demi keselamatan dan keamanan maka perlu pergantian plat.

Hal-hal di atas, poin a sampai $\mathrm{f}$ dapat dipergunakan untuk pertimbangan saja. Namun perbaikan dapat dilaksanakan jika ada kesepakatan dari pemilik kapal.

\section{METODE}

Penelitian dilakukan dengan observasi (observation) atau pengamatan langsung dan ikut serta dalam pekerjaan perbaikan kapal. Penelitian di KM. Harima data yang diperoleh merupakan data kualitatif yaitu hasil dari proses perbaikan kapal KM. Harima. Data yang diperoleh dianalisa dengan metode kualitatif yaitu analisa isi. Analisa isi adalah menganalisa hasil kualitatif dengan teori yang perkapalan (A. Hendrawan et al., 2020).
III. HASIL DAN PEMBAHASAN

Tabel 1. Hasil observasi perbaikan lambung KM

Harima

\begin{tabular}{|l|l|l|}
\hline No. & Jenis Perawatan & \multicolumn{1}{|c|}{ Keterangan } \\
\hline 1. & $\begin{array}{l}\text { Pengecekan } \\
\text { Lambung Kapal }\end{array}$ & $\begin{array}{l}\text { Pengecekan pada seluruh bagian } \\
\text { lambung kapal }\end{array}$ \\
\hline 2. & $\begin{array}{l}\text { pengelasan } \\
\text { Lambung kapal }\end{array}$ & $\begin{array}{l}\text { Pemeriksaan badan kapal dengan } \\
\text { menguji ketebalan pelat kapal dengan } \\
\text { menggunakan bantuan alat ukur. Jika } \\
\text { ketebalan berkurang dan tidak sesuai } \\
\text { standar, maka harus replating pada } \\
\text { kapal siapkan mesin las listrik, palu } \\
\text { ketok, mesin brander potong dan } \\
\text { matri pelat pengganti }\end{array}$ \\
\hline 3. & $\begin{array}{l}\text { Pembersihan } \\
\text { badan kapal }\end{array}$ & $\begin{array}{l}\text { Blasting pembersihan badan kapal } \\
\text { dengan mengemprotkan pasir (steel } \\
\text { grade) yang bertekanan tinggi agar } \\
\text { badan kapal bersih dari kotoraan yang } \\
\text { menempel di badan kapal }\end{array}$ \\
\hline 4. & $\begin{array}{l}\text { Pengecetan } \\
\text { lambung kapal }\end{array}$ & $\begin{array}{l}\text { Melakukan pengecetan ulang } \\
\text { lambung kapal setelah tahap } \\
\text { pembersihan agar pada saat } \\
\text { pengecatan tidak menyebabkan } \\
\text { kondensasi dan lubang lubang kecil } \\
\text { cat terkelupas }\end{array}$ \\
\hline
\end{tabular}

\section{Pengecekan Lambung Kapal}

Pengecekan atau penelitian mana yang rusak dan bocor, tempat yang korosi dan sebagai merupakan bagian pertama yang dilakukan. Menurut (A. Hendrawan et al., 2021) pemeriksaan pada kerusakan atau cacat dalam kapal sangat penting karena hal ini akan mencegah ketidaklayakan operasi. Pemeriksaan yang benar juga akan meningkatkan kinerja kapal lebih lagi akan mencegah kecelakaan kapal. Keselamatan dan kesehatan pelayaran menjadi bagian utama dalam pengoperasian kapal (A. Hendrawan, 2019a, 2020c; A. Hendrawan \& Hendrawan, 2020; A. K. Hendrawan \& Hendrawan, 2020; Tarwaka, 2009)

2. Pengelasan Lambung Kapal

Teknik las yang diterapkan pada lambung kapal memiliki beberapa persyaratan yang ditentukan oleh Badan Klasifikasi yang mengawasi dan memberikan sertifikasi tentang kekuatan konstruksi kapal. Pengelasan kapal harus bisa menjamin dapat mengatasi gaya-gaya hidrostatik kapal dimana merupakan gaya sebagai akibat gelombang samudra. Sebagai alat akut kapal harus mempunyai kekuatan kontruksi yang memadai karena akan mengangkut beban berat.

Untuk memenuhi kualitas pengelasan maka diperlukan tenaga las 
yang profesional sehingga hasil yang diperoleh memenuhi standar. Petugas las harus memiliki sertifikat las yang dikeluarkan pihak yang berwenang. Hasil las pada penyambungan plat memiliki kualitas dan kecepatan yang tinggi dalam pengerjaannya pada akhirnya diharapkan dapat diterima oleh Badan Klasifikasi dan pemilik kapal (Haryadi, 2007).

3. Pembesihan Badan Kapal

Pembersihan badan kapal atau di sebut sandblasting mempunyai tujuan agar karat-karat yang menempel pada lambung kapal bisa hilangkan. Sanblasting juga bermaksud menghilangkan kotoran, lapisan cat pada lambung. Setelah sanblasting maka maka bisa dilakukan replating. Proses Sandblasting merupakan pekerjaan memindahkan pasir sandblast kedalam tempat penampungan, penyaringan pasir, serta memberikan tekanan udara terhadap tangki yang telah berisi pasir, Penembakan/penyemprotan pasir dengan menggunakan pompa nozel sandblast, seperti terlihat pada gambar 1 .

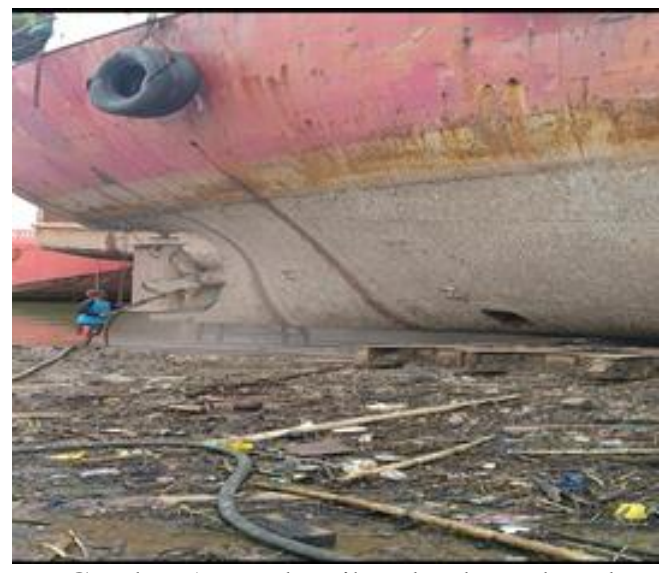

Gambar 1. Pembersihan lambung kapal

Pada proses sandblasting tabung ini dilengkapi katub penghubung udara tekan (kompresor) kemudian nozzle pasir silika disemburkan dengan kecepatan tinggi dan tekanan sekitar 7 $\mathrm{kg} / \mathrm{cm}^{2}$, sampai semburan pada plat baja Mill Scale bisa terkikis. Tumbukan yang terjadi pada semburan pada proses sandblasting dengan permukaan plat akan menghasilkan debu.
Hasil akhir dari sandblasting akan menghasil debu yang berwarna abu-abu keputih-putihan menggumpal seperti awan atau asap. Terdapat material partikel yang bisa menimbulkan kecelakaan kerja karena terpantul kembali setelah semburan sandblasting sehingga perlu diantisipasi dengan menggunakan APD (alat pelindung diri) (Hendrawan et al., 2020; Suryani \& Hendrawan, 2020).

4. Pengecetan Lambung Kapal

Pengecatan lambung kapal berguna melindungi lambung kapal dari proses pengkaratan dan juga binatang laut karena hampir semua bahan pengusun kapal adalah logam (pelat baja) reaktif terhadap korosi sebelum melakukan pengecetan terlebih dahulu dilakukan pembersihan badan kapal sandblasting pengecetan juga bertujuan untuk mengurangi cepatnya korosikorosi. Korosi adalah turunnya kemampuan material logam menerima beban akibat terjadi peristiwa oksidasi

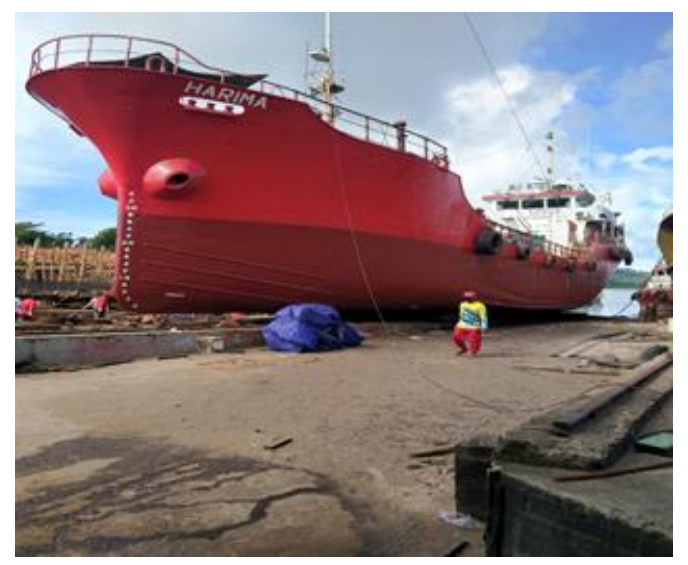

Gambar 2. pengecetan lambung kapal

Pada proses pengecatan peralatan yang dipergunakan antara lain; roll, kuas, dan semprot dengan mempergunakan kompresor. Beberapa cat yang dipergunakan dalam pengecatan lambung kapal:

a. Cat anti karat corrosion (AC).

Dipergunakan dalam Pengecatan badan kapal bagian bawah (keel) sampai dengan bottom.

b. Pengecatan dengan cat anti fouling (AF) dilakukan dalam pencegahan 
penempelan hewan atau tumbuhan laut.

Pada hakikatnya perbaikan dan perawatan kapal adalah bertujuan untuk keselamatan pelayaran. Memastikan semua pada kondisi yang layak untuk berlayar (Marasabessy et al., 2014). Lebih lagi sehat dalam kondisi mesin, maka merupakan tugas bersama antara owner, dan pemerintah bahkan masyarakat untuk mewujudkan keselamatan termasuk kondisi lambung kapal yang baik (A. Hendrawan, 2020a, 2020b; A. Hendrawan \& Hendrawan, 2020; Suryani et al., 2018).

\section{SIMPULAN}

Perbaikan lambung kapal memiliki manfaat terutama keselamatan awak kapal maupun muatan pada saat berlayar seperti kebocoran.

Proses perbaikan lambung kapal anatara lain dengan cara sanblasting, pengelasan, dan pengecatan.

Kapal KM HARIMA melakuan perbaikan lambung kapal seperti replating, blasting,pengecetan.

\section{DAFTAR PUSTAKA}

Ariany, Z. (2014). Kajian Reparasi Pengecatan Pada Lambung Kapal (Studi Kasus Km. Kirana 3). Teknik, 35(1), 27-32. https://doi.org/10.14710/teknik.v35 i1.6822

Haryadi, G. D. (2007). Analisa Kerusakan Hasil Pengelasan Bawah Air Pada Lambung Kapal Dengan Bahan Elektroda Rb 26 Terseloti. Analisa Kerusakan Hasil Pengelasan Bawah Air Pada Lambung Kapal Dengan Bahan Elektroda Rb 26 Terseloti, 9(1), 3141.Rotasi, https://doi.org/10.14710/rotasi.9.1. 31-41

Hendrawan, A. (2019a). Analisa Indikator Keselamatan Pelayaran Pada Kapal Niaga. Saintara, 3(2)

Hendrawan, A. (2019b). Analisa Penyebab Keausan Poros Baling
Baling Kapal. Saintara, 4(1)

Hendrawan, A. (2020a). Analisa Tingkat Kebisingan Kamar Mesin Pada Kapal. Wijayakusuma Prosiding Seminar Nasional: Jaringan Penelitian (JARLIT) Cilacap "Menuju Cilacap 4.C (Creativity, Critical Thingking, Communication And Colaboration, 10-15

Hendrawan, A. (2020b). Pengaruh Turbocharger terhadap Daya Mesin Induk KN. Prajapati. Majalah Ilmiah Gema Maritim, 22(1), 4448. https://doi.org/10.37612/gemamaritim.v22i1.50

Hendrawan, A. (2020c). Program Kesehatan dan Keselamatan Kerja di Atas Kapal. Jurnal Sains Teknologi Transportasi Maritim, 2(1), 1-10.

Hendrawan, A., Ajun, R., Siswadi, \& Supari. (2021). Penyebab Kerusakan Electro Motor Oil Max Pump Pada Mesin Induk Di KM . Dharma Kartika IX. Saintara, 5(2), 28-35

Hendrawan, A., \& Hendrawan, A. K. (2020). Analisa Kebisingan di Bengkel Kerja Akademi Maritim Nusantara. Saintara, 5(1), 1-5

Hendrawan, A., Lusiani, L., \& Aprilian, R. (2020). Sandblasting pada kapal mv. berlian indah, Saintara, 4(2), 26-33

Marasabessy, A., Nur, I., \& Sudjasta, B. (2014). Metode Pemeliharaan Yang Tepat Lambung Kapal Type Patroli V30 Berbahan Fiberglass. Bina Widya, 25(2), 57-65

Satoto, S. W., P, N. A., \& Saputra, H. (2013). Perbandingan Teknis Ukuran Utama Dan Hambatan Kapal Pada Lambung Kapal Wisata Pulau Petong. Jurnal Teknologi Dan Riset Terapan (JATRA), 1(43), 1-10

Suryani, D., Pratiwi, A. Y., Sunarji, \& Hendrawan, A. (2018). Peran Syahbandar Dalam Keselamatan Pelayaran. Jurnal Saintara, 2(2).

Tarwaka. (2009). Keselamatan dan Kesehatan Kerja. Harapan Press. https://doi.org/10.19641/j.cnki.421290/f.2012.03.022 